\title{
A Mineral X-ray Linear Attenuation Coefficient Tool (MXLAC) to Assess Mineralogical Differentiation for X-ray Computed Tomography Scanning
}

\author{
Lunga C. Bam ${ }^{1,2, *}$, Jodie A. Miller ${ }^{1}$ and Megan Becker ${ }^{3}$ (I) \\ 1 Department of Earth Sciences, Stellenbosch University, Private Bag X1, Matieland 7601, South Africa; \\ jmiller@sun.ac.za \\ 2 Department of Radiation Science, South African Nuclear Energy Corporation (Necsa), \\ Pretoria 0001, South Africa \\ 3 Centre for Minerals Research, Department of Chemical Engineering, University of Cape Town, Private Bag, \\ Rondebosch 7701, South Africa; megan.becker@uct.ac.za \\ * Correspondence: lunga.bam@necsa.co.za
}

Received: 9 April 2020; Accepted: 5 May 2020; Published: 15 May 2020

\begin{abstract}
X-ray computed tomography (XCT) is becoming one of the most important techniques in the geosciences. The technique relies on linear attenuation coefficient differences in order to reveal the internal structure of the rocks. In this work, we present a new excel macro tool, called MXLAC, which is a data bank with an excel interface that uses density, X-ray energy and the mineral chemical formula to allow users to calculate mineral linear attenuation coefficients that can then be used to determine discrimination between mineral pairs. Elements within a mineral and specified by the chemical formula, determine how the X-ray beam is attenuated. Analysis of a variety of scanned mineral pairs with similar densities and attenuation coefficients indicates that an attenuation coefficient difference of greater than or equal to $6 \%$ at $45.5 \mathrm{keV}$ effective $\mathrm{X}$-ray energy is required for effective discrimination between two minerals using XCT with single energy scanning. This means that mineral pairs, such as quartz and pyrophyllite cannot be discriminated using the current XCT instruments due to the fact that the attenuation coefficient difference is less than $1.9 \%$ at $45.5 \mathrm{keV}$ effective $\mathrm{X}$-ray energy. Garnets and a variety of other minerals were used as examples to illustrate the importance of knowing the actual chemical formula of the mineral to demonstrate whether they can be partially or fully discriminated from each other.
\end{abstract}

Keywords: X-ray computed tomography; linear attenuation coefficient; minerals; effective $\mathrm{X}$-ray energy

\section{Introduction}

$\mathrm{X}$-ray computed tomography $(\mathrm{XCT})$ is a non-destructive technique that utilizes $\mathrm{X}$-rays to image the 3D internal structure of a wide variety of materials [1-3]. Soon after its development in the medical sciences in the 1970s [4], it attracted considerable attention within the geosciences due to its potential to visualise the internal structure of rocks and minerals [5-7]. In particular, the ability of the technique to determine the mineral content, distribution of minerals, mineral texture, porosity and pore structure network, at a variety of scales, made it an attractive technique across diverse fields from petrology to palaeontology to minerals processing [2,8-11]. Micro and nano XCT has also been used widely to characterize shale gas pore framework [12-14]. XCT has proven to be an important analytical technique for the analysis of drill cores, that lend themselves to analysis because of their uniform sample geometry. Material density [15,16] as well as ore grade [17] have been successfully calculated from drill core using advanced segmentation methods. More recently, it has been proposed to combine XCT with grey level 
co-occurrence matrices (GLCM) to generate algorithms that will automatically interrogate texture in 3D applications using drill core [18].

XCT images record the difference in density by means of grey values that represent the linear attenuation coefficient of each and every mineral present within the specimen [2,7]. The interaction of $X$-rays with minerals depends not only on the mineral density (a function of mineral chemistry and atomic structure) but also on the thickness (grain size) and effective atomic number of the mineral. This means that if the density variation between the minerals present is large, the X-ray beam is attenuated differently, resulting in distinct grey values. This makes the XCT technique attractive to different material science disciplines. However, if the density difference between minerals is small, then it is difficult for XCT to differentiate them because of similar attenuation response of the minerals resulting in similar grey values [2]. Because of this, different combinations of minerals or mineral assemblages are more amenable to interrogation by XCT than others. In particular, some combinations of minerals or mineral pairs cannot be differentiated from one another because of the similarity in attenuation response. In such cases, it is important to know up front, the limitations of the XCT system with respect to the mineral assemblage or problem being worked with.

In this contribution, a simple way to evaluate whether different minerals can be differentiated, on the basis of their linear attenuation coefficient, is presented as the downloadable mineral X-ray linear attenuation coefficient (MXLAC) file. MXLAC represents an attenuation coefficient 'data bank', developed in the form of a user-friendly excel spreadsheet that uses macros to calculate linear attenuation coefficients at any effective energy (with any increment of choice) between 41.7 and $72.6 \mathrm{keV}$ which is equivalent to an X-ray energy spectrum of between 60 and $225 \mathrm{keV}$. The conversion of the $X$-ray energy spectrum to an effective energy that is correlated to the X-ray voltage, is important for XCT users because it allows an accurate calculation of the linear attenuation coefficient for different minerals. An application of MXLAC is demonstrated by looking at several examples including high density iron-ore minerals, some of which cannot be differentiated by XCT.

\section{Methodology}

The development of the MXLAC data bank involved several steps. The first step was to collect different energy spectrums of a tungsten target under a high voltage $(\mathrm{kV})$ and convert them into effective energies equivalent to a monochromatic beam of the $X$-ray energy spectrum. This allows evaluation of how mineralogical grey value information is affected by scanning parameters, different filter materials, sample size and beam hardening by comparing the effective linear attenuation difference with the measured grey value difference. Tungsten is normally used as the target in XCT instruments because it has high flux and can withstand high temperatures. The second step was to collect the National Institute of Standards and Technology (NIST) database for attenuation and energy information for all elements from 41.7 to $72.6 \mathrm{keV}$ and compile this information into an excel spreadsheet. The collected NIST database consists of predetermined energy and linear attenuation coefficient information which prohibit the calculation of linear attenuation coefficient for any X-ray energy increment. To deal with this, different interpolation functions have been incorporated into the spreadsheet in order to calculate linear attenuation coefficient for any X-ray energy. The third step was to develop the excel macros that take the compiled NIST elemental data and convert it to linear attenuation coefficients for any mineral.

\subsection{Tungsten Energy Spectrum}

Different energy spectrums of a tungsten target under a high voltage $(\mathrm{kV})$ were collected using a germanium detector (Figure 1). Although the X-ray system being used to collect the energy spectrums can reach high $X$-ray voltage of $225 \mathrm{kV}$, this level of voltage affects mineralogical discrimination due to smaller linear attenuation coefficient difference. The set voltage on the target is equivalent to the maximum energy of the produced spectrum. The spectrum consists of different proportions of various energies because of the polychromatic nature of the X-ray beam. The varying energy proportions each interact differently with minerals, thus making the associated linear attenuation coefficient calculations 
complex - minerals absorb more energy at the lower energy range compared to the higher energy range of the spectrum. To simplify the interpretation of the interaction of the X-ray spectrum with a mineral, an effective energy of the spectrum was calculated. An effective energy is a weighted average of an actual polychromatic beam. Although previously the effective energy has been assumed to be close to $30-40 \%$ of the peak energy [19], it is more accurate to calculate it for each spectrum.

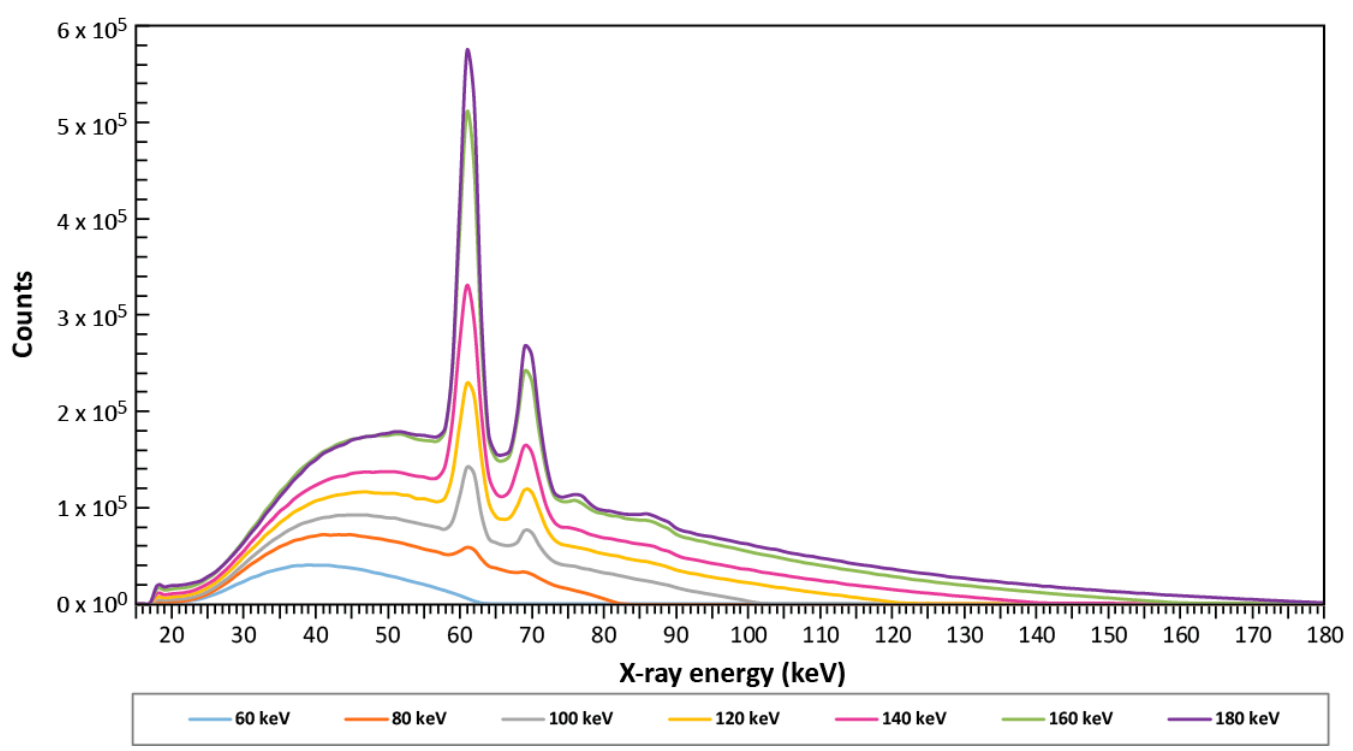

Figure 1. Different tungsten energy spectrums collected at different X-energies [20].

One way to determine the effective energy is to use the aluminium half-value layer method [21-23]. To do this, the effective energy is calculated by converting the X-ray energy spectrum from polychromatic to monochromatic (Figure 2). This is done by combining all the photon energies (E) of the spectrum, relative to the count ratio for each photon energy of the spectrum, using Equations (1) and (2). Equation (1) combines all the counts with respect to each energy of the spectrum. Calculating the effective energy using Equations (1) and (2) is more reliable as compared to calculating it using the mean equation. The mean equation does not take into consideration the counts for each energy photon of the spectrum. The resultant effective energies (Figure 2) calculated using Equation (2) are similar to the ones reported by Yada et al. [23] using the same method.

$$
\text { Count }_{\text {Total }}=\operatorname{Count}_{1}\left(E_{1}\right)+\operatorname{Count}_{2}\left(E_{2}\right)+\ldots+\operatorname{Count}_{n}\left(E_{n}\right)
$$

Effective energy $(\mathrm{keV})=\left[\frac{\operatorname{Count}_{1}\left(E_{1}\right)}{\operatorname{Count}_{\text {Total }}}\right] \times E_{1}+\left[\frac{\operatorname{Count}_{2}\left(E_{2}\right)}{\operatorname{Count}_{\text {Total }}}\right] \times E_{2}+\ldots+\left[\frac{\operatorname{Count}_{n}\left(E_{n}\right)}{\operatorname{Count}_{\text {Total }}}\right] \times E_{2}$

Conversion of the spectrum into a single energy simplifies the linear attenuation coefficient calculations. In addition to this, it allows a direct comparison of theoretically calculated linear attenuation coefficients with the experimental ones. This means that the calculated linear attenuation coefficients can be used to predict how minerals will correlate with grey values on radiographs or 2D image slices taken from 3D image volumes. Grey values are a direct representation of the average linear attenuation coefficients of minerals [24,25]. Where samples are high density or larger volume, it can be difficult to calculate accurate linear attenuation coefficients since the X-ray beam is hardened as it passes through the sample [26] causing the effective energy to be higher [27]. This will affect the expected discrimination between the mineralogical information based on the initially calculated linear attenuation coefficients. Therefore, in such a case, a step-wise protocol should be used to determine what is affecting the discrimination between the minerals. 


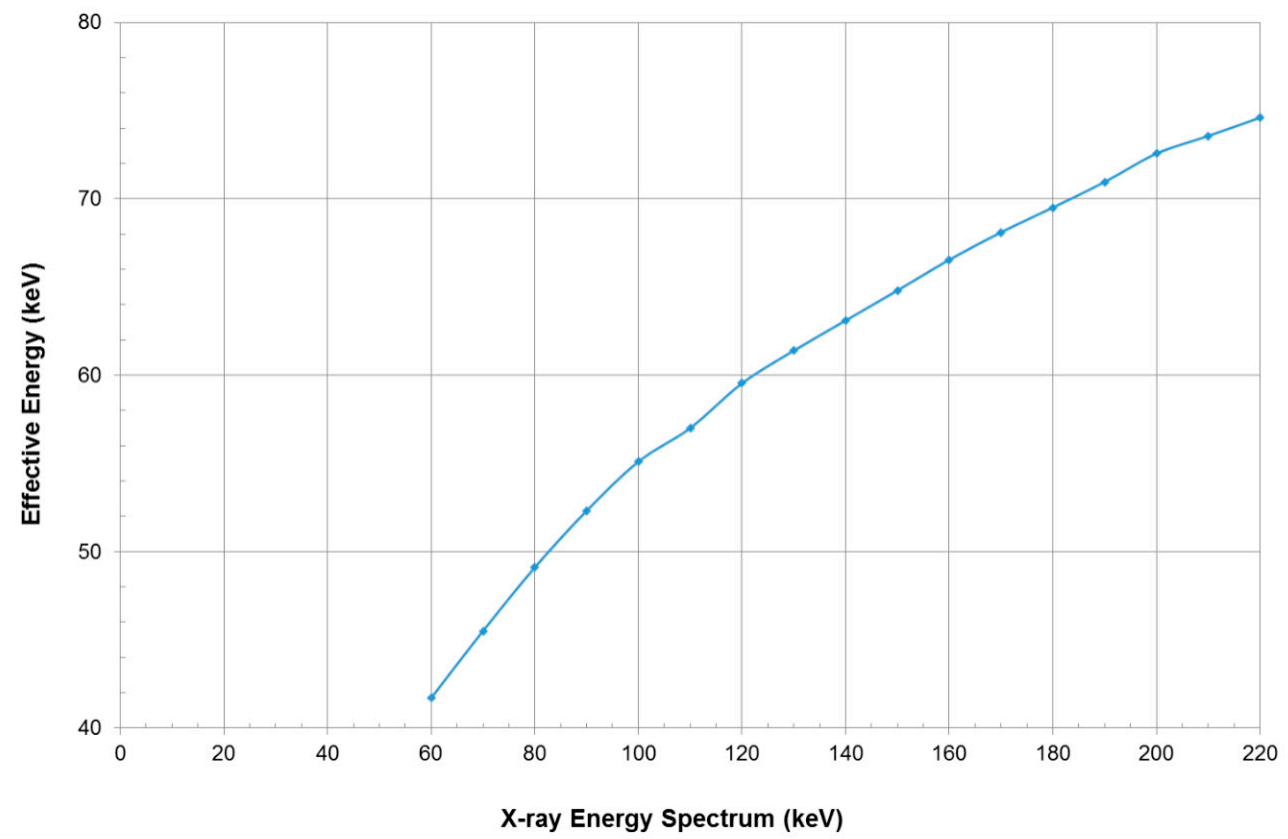

Figure 2. Correlation between the effective $X$-ray energy and the $X$-ray energy spectrum of the tungsten target [20].

\subsection{Development of the Attenuation Coefficient Data Bank}

The mass attenuation coefficient data from NIST represent the mass attenuation coefficients for all elements at different X-ray energies (http://physics.nist.gov/PhysRefData/XrayMassCoef/tab3.html). In order to properly utilise the mass attenuation coefficient data for discrete $\mathrm{X}$-ray energies or X-ray energies similar to the collected spectrums mentioned above, a set of linear and polynomial equations (Equations (3)-(5)) were fitted to represent the change of mass attenuation coefficient as the X-ray energy increases (Figure 3). Iron has been used as an example to illustrate the decreasing mass attenuation coefficient with increasing X-ray energy and the spike in mass attenuation coefficient at $7.112 \mathrm{keV}$ is due to a K-edge absorption. These equations were fitted for all elements in the periodic table taking into consideration the behaviour of mass attenuation coefficients with respect to energy. Fitting different equations was done to minimise deviations between the expected mass attenuation coefficients with the calculated ones.

$$
\begin{gathered}
y=m x+c \\
y=a x^{2}+b x+c \\
y=a x^{5}+b x^{4}+c x^{3}+d x^{2}+e x+f
\end{gathered}
$$

The $\mathrm{x}$ and $\mathrm{y}$-axis represents the $\mathrm{X}$-ray energy and mass attenuation coefficient respectively. This method was repeated for all the elements. In cases where Equations (3) and (4) could not provide satisfactory mass attenuation coefficients, Equation (5) (high order polynomial) was used to minimize deviations between the mass attenuation coefficient calculated in this spreadsheet and that provided by NIST. The mass attenuation coefficient for minerals, $\mu / \rho\left(\mathrm{cm}^{2} / \mathrm{g}\right)$, was calculated using Equation (6) where $\omega_{i}$ is the weight fraction of $i$ th element [24,25]. The linear attenuation coefficient, $\mu\left(\mathrm{cm}^{-1}\right)$, was then obtained by rearranging Equation (6) to give Equation (7).

$$
\begin{gathered}
\frac{\mu}{\rho}=\Sigma_{i}\left(\frac{\mu}{\rho}\right)_{i} \times \omega_{i} \\
\mu=\left[\Sigma_{i}\left(\frac{\mu}{\rho}\right)_{i} \times \omega_{i}\right] \rho
\end{gathered}
$$




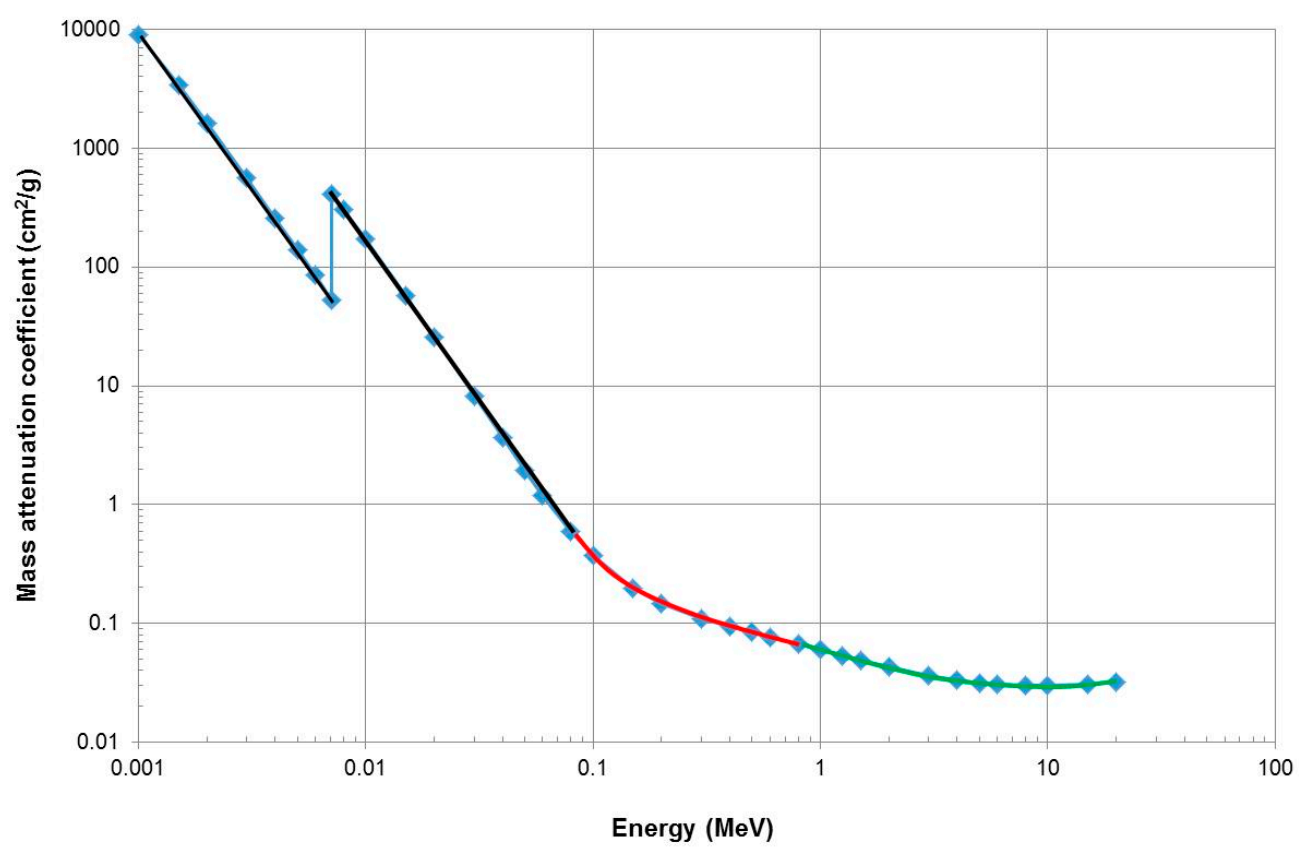

Figure 3. The representation of iron mass attenuation coefficient by different equations (linear, second and fifth order polynomial). The black lines represent linear equations (Equation (1)) and the red and green curves represent the second and fifth order polynomial equations (Equations (2) and (3)).

\subsection{Development of User Spreadsheet}

The MXLAC spreadsheet (also provided as Supplementary Materials) calculates the linear attenuation coefficient as an output using Equation (7). The spreadsheet is designed to be user-friendly with minimal inputs required to immediately calculate the linear attenuation coefficient for any mineral and can accommodate complex mineral compositions. Calculating the linear attenuation coefficient of different minerals requires a user to insert the actual number of elements (both cations and anions) present within a mineral (i.e., the exact mineral composition), the mineral density and the relevant effective energy under the appropriate columns (Figure 4). MXLAC can calculate the linear attenuation coefficient of the same or different mineral at two different energies simultaneously. This allows a direct comparison of the linear attenuation coefficient of minerals to better understand the impact of grey value variation on image slices in order to optimize mineralogical discrimination prior to scanning. The voltage is equivalent to the energy spectrum indicated in the column for the tungsten spectrum. The effective energy is converted from the tungsten spectrum and is utilized to calculate the linear attenuation coefficient as an output under the X-ray attenuation coefficient cell.

\subsection{Validation of Linear Attenuation Coefficients}

To validate the ability of MXLAC to predict mineral discrimination using linear attenuation coefficients, thirteen minerals were scanned using a micro-focus X-ray computed tomography system (Nikon XTH 225 ST) and their grey values compared. Prior to scanning, the minerals were grouped as follows based on linear attenuation coefficient and mineral density: (a) almandine, andradite and grossular; (b) quartz, kaolinite, dolomite, calcite; (c) fluorite, apatite; and (d) goethite, chromite, magnetite and hematite. The density information for all the minerals was obtained from https: //www.mindat.org. All the minerals were scanned at $70 \mathrm{kV}$ (45.5 keV effective energy) using different filter materials as well as having no filter (Table 1). The set voltage on the target represents the collected energy spectrum with a maximum energy of $70 \mathrm{keV}$. The samples were scanned at a $20 \mu \mathrm{m}$ resolution with 3000 projections and $4 \mathrm{~s}$ exposure time. The selection of a high number of projections and high exposure time optimises mineralogical discrimination using grey values and minimises image noise associated with a low number of projections and low exposure time. The scanned 
data were reconstructed using CT Pro 3D software version 3.1 .9 by applying various built-in beam hardening correction factors within the software. The mean grey value analysis was conducted in all the samples using VG Studio Max version 3.2 software to determine the required grey value difference that renders minerals to be discriminated. Before the grey value analysis was conducted, the region growing tool was used to remove background information from all the minerals in order to deal only with the mineral grey values themselves. It was important to define the mineral grey value range because it was used to assign a false colour to the individual minerals in order to determine how grey values of different minerals overlap with each other. The mineral identities, compositions, as well as compositional homogeneity were confirmed using both standardized scanning electron microscopy (SEM) and quantitative evaluation of materials by scanning electron microscopy (QEMSCAN). Individual minerals were prepared into polished sections and characterised using an FEI QEMSCAN 650F instrument on the field image analysis routine at the University of Cape Town. Measurements were run at $25 \mathrm{kV}, 10 \mathrm{nA}$ using a 100 micron pixel spacing. The same sections were then used for SEM-EDS analysis conducted at the Electron Microscopy Unit of the Central Analytical Facility (Stellenbosch University, South Africa) using Zeiss EVO MA15VP Scanning Electron Microscope. The measurements were run at between $20 \mathrm{kV}$ to $30 \mathrm{kV}$, with a working distance for EDS analyses of $8.5 \mathrm{~mm}$ and magnifications ranging between $1000 \times$ and 5000x. Appropriate ASTIMEX@ certified mineral standards were used for different element concentrations even within similar mineral families, such as garnet (e.g., almandine, andradite and grossular). The validation process also provided information about possible inclusions that may: (a) affect expected discrimination between minerals and (b) provide a false assumption that a mineral can be discriminated from another mineral due to the presence of non-uniformly distributed inclusions that cannot be easily detected by the XCT scanning resolution.

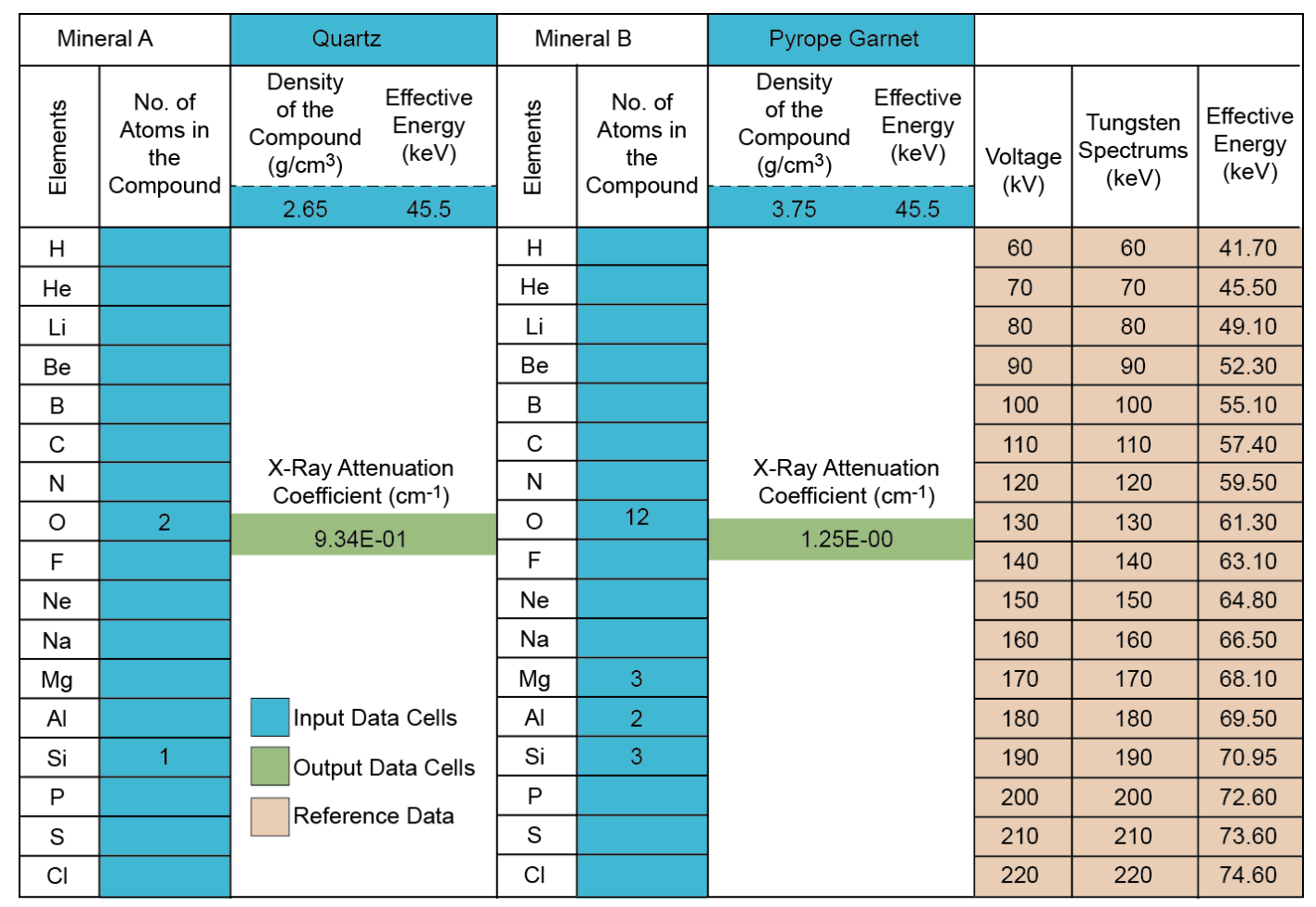

Figure 4. Illustration of the MXLAC user interface for calculation of mineral linear attenuation coefficients, with inputs under number of atoms in the compound, density and voltage for each mineral indicated in blue. The calculated output is show in green. 
Table 1. Scanning parameters to optimize discrimination between minerals.

\begin{tabular}{cccc}
\hline Exposure Time (sec) & No. of Projections & $\begin{array}{c}\text { Voltage (kV)/ } \\
\text { Effective Energy (keV) }\end{array}$ & Filter Material \\
\hline 4 & 3000 & $70 / 45.5$ & No filter \\
4 & 3000 & $70 / 45.5$ & $0.25 \mathrm{~mm} \mathrm{Cu}$ \\
4 & 3000 & $70 / 45.5$ & $1 \mathrm{~mm} \mathrm{Al}+1 \mathrm{~mm} \mathrm{Cu}$ \\
\hline
\end{tabular}

\section{Results}

Here we present the results of this study in two parts. In the first part, we use MXLAC to calculate linear attenuation coefficients for a variety of minerals of varying compositional complexity using the compiled spreadsheet. These values are compared to those that can be generated using the NIST database to assess the accuracy of the MXLAC spreadsheet. Thereafter, mineral linear attenuation coefficients, calculated using MXLAC, are compared with the mineral grey values, generated using $\mathrm{XCT}$, to evaluate the minimum difference in attenuation coefficient needed to be able to discriminate two minerals using XCT.

\subsection{Calculated Linear Attenuation Coefficients}

Table 2 lists a wide range of minerals ( 40 in total) with different densities and chemical compositions. The 40 minerals were picked to evaluate different mineral compositional complexity in terms of both the range of elements present in the mineral as well as the mineral structure. It includes minerals regarded as ore minerals (e.g., chalcopyrite, hematite and sphalerite), clay minerals (e.g., kaolinite), carbonates (e.g., calcite and dolomite) and end-member varieties of the same mineral (e.g., pyrope, almandine, grossular, andradite and spessartine garnets). The maximum $\%$ error difference between the calculated linear attenuation coefficients using MXLAC and those given by the NIST database, is $4.96 \%$ at $44.79 \mathrm{keV}$ and $4.81 \%$ at $62.53 \mathrm{keV}$. At $44.79 \mathrm{keV}$, nine minerals have a \% error less than $2 \%$, whilst at $62.53 \mathrm{keV}, 22$ minerals have a \% error less than $2 \%$ (Table 2). The X-ray energy of $44.79 \mathrm{keV}$ and $62.53 \mathrm{keV}$ from the NIST database were selected as they are sufficiently close enough to the calculated effective energy of the energy spectrums collected at the voltage of $70 \mathrm{kV}$ and $140 \mathrm{kV}$ respectively. This provides more information about the expected \% error at both $70 \mathrm{kV}$ and $140 \mathrm{kV}$. The calculated mineral linear attenuation coefficients increase with increasing density, but the trend is not linear and the mineral attenuation is lower at $62.53 \mathrm{keV}$ as expected (Figure 5). Interrogation of the data indicates that it is not possible to predict the linear attenuation coefficient based on mineral density alone. Comparison of sphalerite and corundum for example, shows similar densities $\left(4.1 \mathrm{~g} / \mathrm{cm}^{3}\right.$ and $4.02 \mathrm{~g} / \mathrm{cm}^{3}$ respectively) but large differences in linear attenuation coefficient $\left(11.9 \mathrm{~cm}^{-1}\right.$ and $1.34 \mathrm{~cm}^{-1}$, respectively). Because the minerals have similar densities, the logical assumption would be that these minerals cannot be differentiated using XCT, which would be incorrect, based on the difference in their linear attenuation coefficients.

In contrast, dolomite and corundum have similar attenuation coefficients $\left(1.33 \mathrm{~cm}^{-1}\right.$ and $1.34 \mathrm{~cm}^{-1}$ respectively) suggesting they cannot be differentiated using XCT, but these two minerals have significant differences in density $\left(2.85 \mathrm{~g} / \mathrm{cm}^{3}\right.$ and $4.02 \mathrm{~g} / \mathrm{cm}^{3}$ respectively). In this case, the difference in density would suggest these minerals can be differentiated using XCT, which is not true, based on the linear attenuation coefficient information. The above examples illustrate the complexity of trying to evaluate whether XCT is useful for different mineral pairs, although the likelihood of dolomite and corundum naturally occurring in the same rock is low. A more likely combination is dolomite and calcite. In this case, the density of calcite is $2.71 \mathrm{~g} / \mathrm{cm}^{3}$ in comparison to the $2.85 \mathrm{~g} / \mathrm{cm}^{3}$ of dolomite and the linear attenuation of calcite is $1.73 \mathrm{~cm}^{-1}$ in comparison to the $1.33 \mathrm{~cm}^{-1}$ of dolomite. In this example, it is unclear if these differences are large enough to be able to differentiate these minerals using XCT. Therefore, the second part of the results presented here, uses MXLAC to evaluate the minimum difference in linear attenuation coefficient needed to differentiate two minerals. 


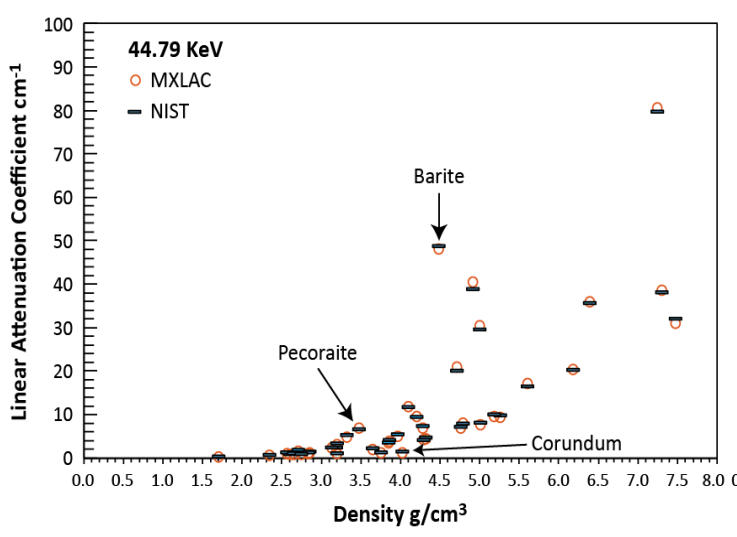

A

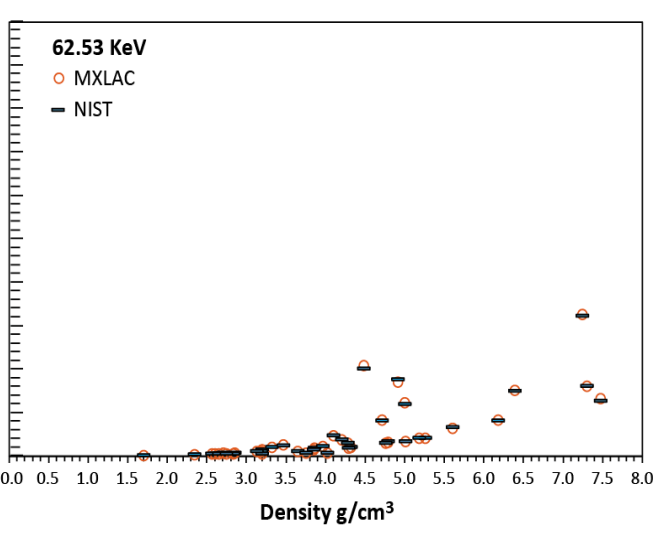

B

Figure 5. Variation of linear attenuation coefficients for different mineral densities calculated with MXLAC and NIST at: (A) $44.79 \mathrm{keV}$ and (B) $62.53 \mathrm{keV}$ X-ray energy.

\subsection{Minimum Attenuation Coefficient Difference to Determine Discrimination}

XCT, SEM-EDS and QEMSCAN analysis was undertaken on 13 minerals from Table 2 which provided data that could be properly interrogated for grey level variation (Figure 6 and Table 3). Table 4 shows comparison of different mineral pairs from these 13 minerals. The pairs are based on minerals occurring in the same QEMSCAN polished mount so that the grey values are comparable and reflect the linear attenuation coefficient (Figure 6). Minerals with a linear attenuation coefficient less than $2 \mathrm{~cm}^{-1}$ did not require the utilisation of any filters to optimize grey value variation. This is demonstrated by quartz, kaolinite, dolomite and calcite (Figure 6D-G) respectively). However, minerals with a linear attenuation coefficient more than $3 \mathrm{~cm}^{-1}$ required application of a filter in order to optimise $X$-ray penetration and minimise beam hardening. In the case of magnetite and hematite (Figure $6 \mathrm{~L}, \mathrm{M}$ ), the highest density minerals examined, a combination of filter materials and high beam hardening correction factor was used to minimise the impact of beam hardening.

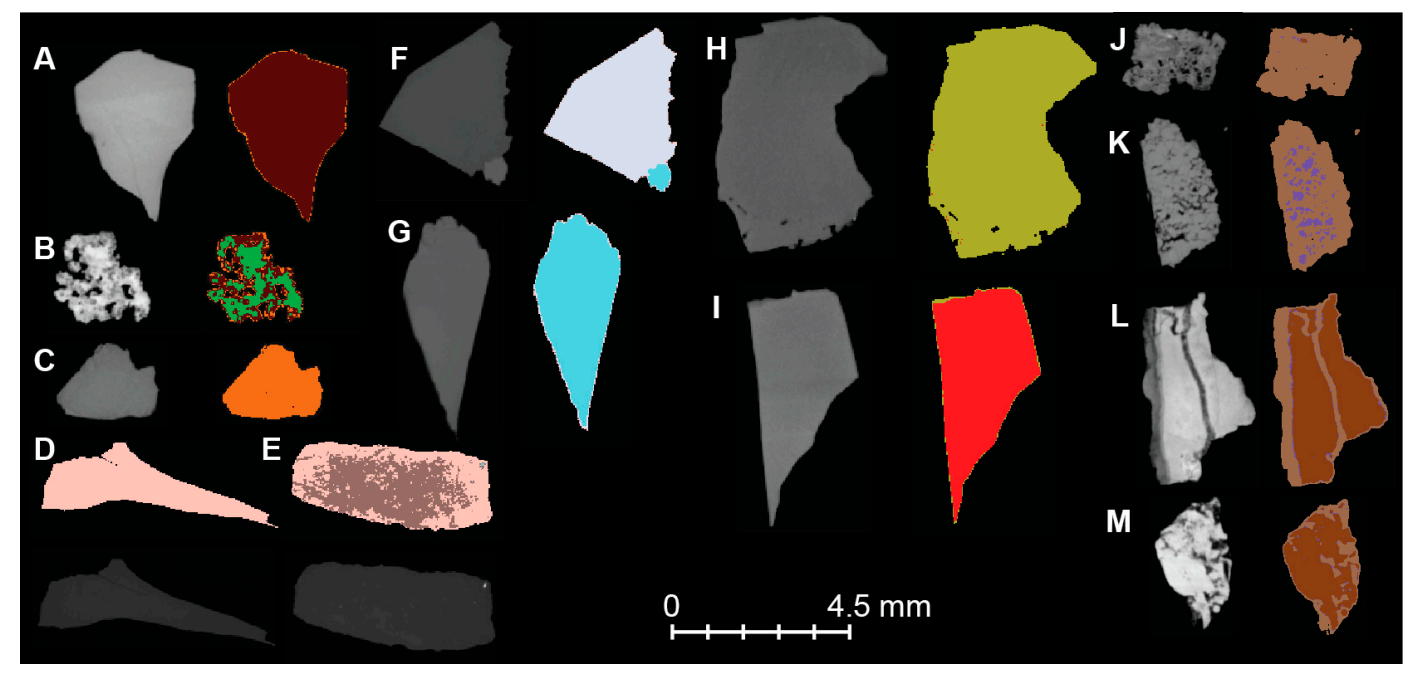

Figure 6. Grey value variation of different minerals with their corresponding false colour to illustrate discrimination between minerals at $45.5 \mathrm{keV}$ effective energy: (A) almandine, (B) andradite, (C) grossular, (D) quartz, (E) kaolinite, (F) dolomite, (G) calcite, (H) apatite, (I) fluorite, (J) goethite, (K) chromite, (L) magnetite and (M) hematite. 
Table 2. Comparison of the NIST and MXLAC attenuation coefficients for different types of minerals.

\begin{tabular}{|c|c|c|c|c|c|c|c|c|}
\hline \multirow[b]{2}{*}{ Mineral. } & \multirow[b]{2}{*}{ Chemical Formula } & \multirow[b]{2}{*}{$\begin{array}{l}\text { Density } \\
\left(\mathrm{g} / \mathrm{cm}^{3}\right)\end{array}$} & NIST & MXLAC & \multirow[b]{2}{*}{$\%$ Error } & NIST & MXLAC & \multirow[b]{2}{*}{$\%$ Error } \\
\hline & & & \multicolumn{2}{|c|}{$\begin{array}{c}\text { Attenuation } \\
\text { Coefficient }\left(\mathrm{cm}^{-1}\right) \text {, } \\
\text { at } 44.79 \mathrm{keV}\end{array}$} & & \multicolumn{2}{|c|}{$\begin{array}{c}\text { Attenuation } \\
\text { Coefficient }\left(\mathrm{cm}^{-1}\right) \text {, } \\
\text { at } 62.53 \mathrm{keV}\end{array}$} & \\
\hline Acanthite & $\mathrm{Ag}_{2} \mathrm{~S}$ & 7.24 & 79.68 & 80.60 & 1.14 & 32.43 & 32.70 & 0.83 \\
\hline Almandine & $\mathrm{Fe}_{3} \mathrm{Al}_{2} \mathrm{Si}_{3} \mathrm{O}_{12}$ & 4.32 & 4.77 & 4.55 & 4.56 & 2.21 & 2.19 & 0.53 \\
\hline Andradite & $\mathrm{Ca}_{3} \mathrm{Fe}^{3+}{ }_{2} \mathrm{Si}_{3} \mathrm{O}_{12}$ & 3.86 & 4.09 & 3.91 & 4.44 & 1.91 & 1.90 & 0.35 \\
\hline Ankerite & $\mathrm{CaFe}\left(\mathrm{CO}_{3}\right)_{2}$ & 3.20 & 3.33 & 3.19 & 4.20 & 1.56 & 1.56 & 0.00 \\
\hline Apatite & $\mathrm{Ca}_{5}\left(\mathrm{PO}_{4}\right)_{3} \mathrm{OH}$ & 3.19 & 2.36 & 2.28 & 3.39 & 1.19 & 1.19 & 0.00 \\
\hline Arsenopyrite & FeAsS & 6.18 & 20.23 & 20.40 & 0.83 & 8.26 & 8.51 & 2.94 \\
\hline Barite & $\mathrm{BaSO}_{4}$ & 4.48 & 48.67 & 48.10 & 1.17 & 20.31 & 21.00 & 3.29 \\
\hline Borax & $\mathrm{Na}_{2} \mathrm{~B}_{4} \mathrm{O}_{5}(\mathrm{OH})_{4} \cdot 8 \mathrm{H}_{2} \mathrm{O}$ & 1.70 & 0.42 & 0.41 & 3.02 & 0.34 & 0.33 & 2.94 \\
\hline Calcite & $\mathrm{CaCO}_{3}$ & 2.71 & 1.80 & 1.73 & 4.09 & 0.94 & 0.94 & 0.54 \\
\hline Carnotite & $\mathrm{K}_{2}\left(\mathrm{UO}_{2}\right)_{2}\left(\mathrm{VO}_{4}\right)_{2} \cdot 3 \mathrm{H}_{2} \mathrm{O}$ & 4.91 & 38.90 & 40.60 & 4.19 & 17.83 & 17.20 & 3.53 \\
\hline Chalcocite & $\mathrm{Cu}_{2} \mathrm{~S}$ & 5.60 & 16.48 & 17.20 & 4.19 & 6.72 & 6.49 & 3.42 \\
\hline Chalcopyrite & $\mathrm{CuFeS}_{2}$ & 4.20 & 9.48 & 9.58 & 1.04 & 3.95 & 3.89 & 1.52 \\
\hline Chlorite & $(\mathrm{Mg})_{5} \mathrm{Al}_{2} \mathrm{Si}_{3} \mathrm{O}_{10}(\mathrm{OH})_{8}$ & 3.20 & 1.09 & 1.04 & 4.44 & 0.73 & 0.72 & 1.30 \\
\hline Chromite & $\mathrm{FeCr}_{2} \mathrm{O}_{4}$ & 4.79 & 7.93 & 8.03 & 1.21 & 3.42 & 3.40 & 0.55 \\
\hline Corundum & $\mathrm{Al}_{2} \mathrm{O}_{3}$ & 4.02 & 1.41 & 1.34 & 4.96 & 0.92 & 0.91 & 1.09 \\
\hline Dolomite & $\mathrm{CaMg}\left(\mathrm{CO}_{3}\right)_{2}$ & 2.85 & 1.39 & 1.33 & 4.32 & 0.80 & 0.80 & 0.00 \\
\hline Fluorite & $\mathrm{CaF}_{2}$ & 3.13 & 2.50 & 2.41 & 3.76 & 1.23 & 1.23 & 0.38 \\
\hline Gibbsite & $\mathrm{Al}(\mathrm{OH})_{3}$ & 2.34 & 0.74 & 0.70 & 4.89 & 0.52 & 0.51 & 2.16 \\
\hline Goethite & $\mathrm{FeO}(\mathrm{OH})$ & 4.28 & 7.34 & 7.01 & 4.49 & 3.17 & 3.16 & 0.22 \\
\hline Grossular & $\mathrm{Ca}_{3} \mathrm{Al}_{2} \mathrm{Si}_{3} \mathrm{O}_{12}$ & 3.65 & 2.22 & 2.12 & 4.45 & 1.19 & 1.18 & 0.77 \\
\hline Hematite & $\mathrm{Fe}_{2} \mathrm{O}_{3}$ & 5.26 & 9.89 & 9.45 & 4.48 & 4.21 & 4.20 & 0.16 \\
\hline Ilmenite & $\mathrm{FeTiO}_{3}$ & 4.76 & 7.26 & 6.95 & 4.34 & 3.17 & 3.13 & 1.05 \\
\hline Kaolinite & $\mathrm{Al}_{2} \mathrm{Si}_{2} \mathrm{O}_{5}(\mathrm{OH})_{4}$ & 2.60 & 0.91 & 0.87 & 4.90 & 0.60 & 0.59 & 1.95 \\
\hline K-feldspar & $\mathrm{KAlSi}_{3} \mathrm{O}_{8}$ & 2.56 & 1.22 & 1.16 & 4.65 & 0.71 & 0.71 & 0.00 \\
\hline Lepidolite & $\mathrm{KLi}_{2} \mathrm{AlSi}_{4} \mathrm{O}_{10}(\mathrm{OH})_{2}$ & 2.83 & 1.21 & 1.16 & 4.45 & 0.74 & 0.73 & 1.35 \\
\hline Magnetite & $\mathrm{Fe}_{3} \mathrm{O}_{4}$ & 5.18 & 10.03 & 9.58 & 4.48 & 4.25 & 4.25 & 0.14 \\
\hline Molybdenite & $\mathrm{MoS}_{2}$ & 5.00 & 29.65 & 30.50 & 2.79 & 12.03 & 12.50 & 3.76 \\
\hline Olivine & $\mathrm{Fe}_{2} \mathrm{SiO}_{4}$ & 3.32 & 5.20 & 4.97 & 4.42 & 2.27 & 2.26 & 0.44 \\
\hline Pecoraite & $\mathrm{Ni}_{3} \mathrm{~S}_{2} \mathrm{O}_{5}\left(\mathrm{OH}_{4}\right)$ & 3.47 & 6.65 & 6.92 & 3.87 & 2.57 & 2.70 & 4.81 \\
\hline Pyrite & $\mathrm{FeS}_{2}$ & 5.01 & 8.02 & 7.81 & 2.52 & 3.48 & 3.50 & 0.63 \\
\hline Pyrope & $\mathrm{Mg}_{3} \mathrm{Al}_{2} \mathrm{Si}_{3} \mathrm{O}_{12}$ & 3.75 & 1.34 & 1.28 & 4.51 & 0.87 & 0.86 & 1.30 \\
\hline Quartz & $\mathrm{SiO}_{2}$ & 2.65 & 1.01 & 0.96 & 4.95 & 0.64 & 0.63 & 1.68 \\
\hline Rynersonite & $\mathrm{CaTa}_{2} \mathrm{O}_{6}$ & 6.39 & 35.64 & 36.00 & 0.99 & 15.13 & 15.20 & 0.46 \\
\hline Safflorite & $\mathrm{CoAs}_{2}$ & 7.47 & 32.11 & 31.10 & 3.13 & 12.91 & 13.40 & 3.66 \\
\hline Siderite & $\mathrm{FeCO}_{3}$ & 3.96 & 5.41 & 5.17 & 4.47 & 2.41 & 2.40 & 0.35 \\
\hline Spessartine & $\mathrm{Mn}_{3} \mathrm{Al}_{2} \mathrm{Si}_{3} \mathrm{O}_{12}$ & 4.29 & 4.22 & 4.33 & 2.51 & 2.00 & 1.98 & 0.94 \\
\hline Sphalerite & $\mathrm{ZnS}$ & 4.10 & 11.68 & 11.90 & 1.82 & 4.78 & 4.80 & 0.42 \\
\hline Talc & $\mathrm{Mg}_{3} \mathrm{Si}_{4} \mathrm{O}_{10}(\mathrm{OH})_{2}$ & 2.75 & 0.99 & 0.94 & 4.85 & 0.64 & 0.64 & 0.00 \\
\hline Uvarovite & $\mathrm{Ca}_{3} \mathrm{Cr}_{2} \mathrm{Si}_{3} \mathrm{O}_{12}$ & 3.85 & 3.55 & 3.55 & 0.15 & 1.70 & 1.69 & 0.69 \\
\hline Wolframite & $\mathrm{FeWO}_{4}$ & 7.30 & 38.12 & 38.70 & 1.50 & 16.16 & 16.30 & 0.86 \\
\hline Zircon & $\mathrm{ZrSiO}_{4}$ & 4.71 & 20.06 & 21.10 & 4.94 & 8.26 & 8.40 & 1.67 \\
\hline
\end{tabular}

Evaluating the required linear attenuation coefficient difference to determine discrimination between minerals is not trivial. This is due to grey value overlap between minerals which cannot be avoided in most cases, when using XCT. Partly this is because most naturally occurring minerals have inclusions of other minerals in them to some extent. This is well demonstrated by the quartz and kaolinite samples used here. The calculated linear attenuation coefficient difference between these minerals is $9.42 \%$. However, the measured grey value difference between these two minerals was determined to be $4.31 \%$, resulting in only partial discrimination (Figure 6D,E). The grey value overlap is due to the presence of small inclusions of quartz and k-feldspar in the kaolinite (Figure 7). Figure 6 is given at such a resolution that the small inclusions cannot be seen but the QEMSCAN analysis supports their presence. A similar situation exists between goethite and chromite (Figure 6J,K) where the linear attenuation coefficient difference is higher $(12.99 \%)$ but the grey value difference is lower (7.1\%), resulting in only partial discrimination of the two minerals. In this case, the grey value overlap is due to different Fe-concentrations within the goethite matrix. In some cases, the presence of mineral inclusions does not affect the mineral discrimination but still affects the mean grey value that is supposed to represent the true linear attenuation coefficient. This is a case with almandine, which has a higher linear attenuation coefficient than andradite, but has a lower mean grey value (Table 3 and Figure 7) due to the presence of uniformly distributed pyrope and minor grossular as 
inclusions. Despite the presence of these mineral inclusions in almandine, almandine was clearly discriminated from andradite with a grey value difference of $18.76 \%$ and a linear attenuation coefficient difference of $14.22 \%$ (Table 4 and Figure 6). Similarly, apatite and fluorite (Figure $6 \mathrm{H}, \mathrm{I}$ ) are completely discriminated from one another in terms of their grey value levels $(9.26 \%)$ but have a lower linear attenuation coefficient difference $(6.06 \%)$. This is attributed to the fact that there are no inclusions within the minerals. This shows that a minimum linear attenuation coefficient difference of $6 \%$ is enough to discriminate between minerals. Minerals with linear attenuation coefficient difference less than this may be difficult to discriminate. Hematite and magnetite have a linear attenuation coefficient difference of $1.42 \%$ with a density difference of $1.54 \%$, resulting in a grey value difference of $4.27 \%$. Therefore, hematite and magnetite cannot be discriminated from each other according to Figure 6. Thus, it would seem that minerals with a linear attenuation coefficient difference of less than $\sim 4.3 \%$ cannot be differentiated using XCT, whereas minerals with a linear attenuation coefficient difference above $\sim 6 \%$ can be differentiated. However, this assumes that the target material is tungsten, minerals are pure and free of inclusions. If the minerals are not compositionally pure then the presence of inclusions complicates discrimination as in the case of the quartz and kaolinite samples used here. In addition to this, different target materials (e.g., Silver, Copper, Molybdenum) would have different effective energies at the same $X$-ray voltage but the minimum required attenuation coefficient difference is expected to remain the same. This means that the X-ray voltage for each target material would be different in order to achieve the same minimum required attenuation coefficient difference to differentiate minerals.

Table 3. Grey value variation of different minerals with their corresponding density (https://www. mindat.org/) and linear attenuation coefficients at $45.5 \mathrm{keV}$ effective energy.

\begin{tabular}{|c|c|c|c|c|}
\hline Mineral & Chemical Formula & Density $\mathrm{g} / \mathrm{cm}^{3}$ & Attenuation Coefficient $\mathrm{cm}^{-1}$ & Mean Grey Value \\
\hline Almandine & $\mathrm{Fe}_{3} \mathrm{Al}_{2} \mathrm{Si}_{3} \mathrm{O}_{12}$ & 4.32 & 4.36 & $28,084.5$ \\
\hline Andradite & $\mathrm{Ca}_{3} \mathrm{Fe}^{3+}{ }_{2} \mathrm{Si}_{3} \mathrm{O}_{12}$ & 3.86 & 3.74 & $34,569.4$ \\
\hline Grossular & $\mathrm{Ca}_{3} \mathrm{Al}_{2} \mathrm{Si}_{3} \mathrm{O}_{12}$ & 3.65 & 2.05 & $22,971.9$ \\
\hline Quartz & $\mathrm{SiO}_{2}$ & 2.65 & 0.93 & $10,540.6$ \\
\hline Kaolinite & $\mathrm{Al}_{2} \mathrm{Si}_{2} \mathrm{O}_{5}(\mathrm{OH})_{4}$ & 2.60 & 0.85 & $11,014.9$ \\
\hline Dolomite & $\mathrm{CaMg}\left(\mathrm{CO}_{3}\right)_{2}$ & 2.85 & 1.29 & $15,047.8$ \\
\hline Calcite & $\mathrm{CaCO}_{3}$ & 2.71 & 1.66 & $18,285.0$ \\
\hline Fluorite & $\mathrm{CaF}_{2}$ & 3.13 & 2.31 & $23,956.0$ \\
\hline Apatite & $\mathrm{Ca}_{5}\left(\mathrm{PO}_{4}\right)_{3} \mathrm{OH}$ & 3.15 & 2.15 & $21,737.9$ \\
\hline Goethite & $\mathrm{FeO}(\mathrm{OH})$ & 4.28 & 6.70 & $36,097.6$ \\
\hline Chromite & $\mathrm{FeCr}_{2} \mathrm{O}_{4}$ & 4.79 & 7.70 & $38,856.9$ \\
\hline Magnetite & $\mathrm{Fe}_{3} \mathrm{O}_{4}$ & 5.18 & 9.15 & $54,895.8$ \\
\hline Hematite & $\mathrm{Fe}_{2} \mathrm{O}_{3}$ & 5.26 & 9.02 & $57,344.8$ \\
\hline
\end{tabular}

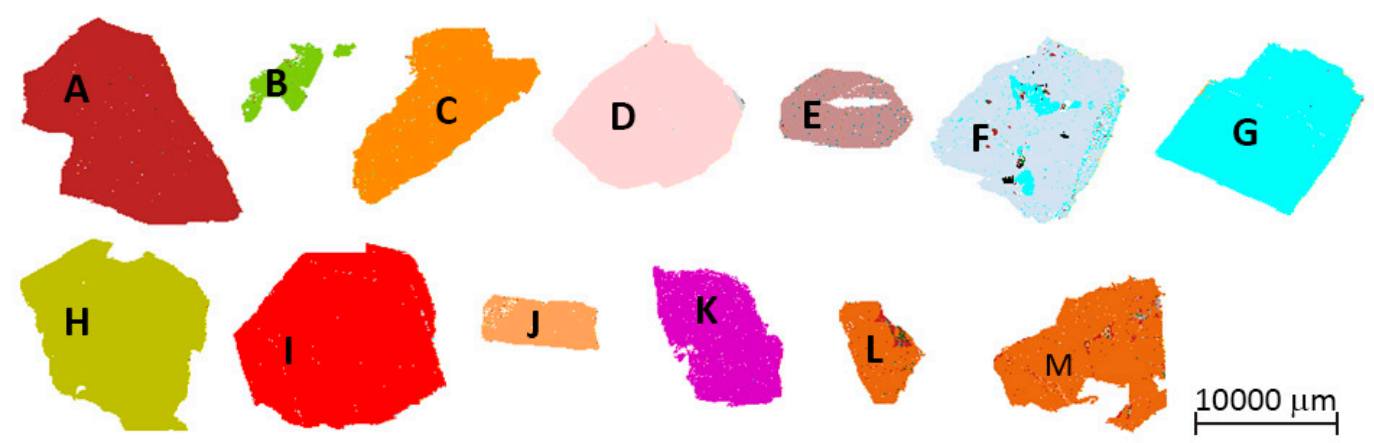

Figure 7. Mineral classification using QEMSCAN in order to understand the discrimination between the minerals: (A) almandine, (B) andradite, (C) grossular, (D) quartz, (E) kaolinite, (F) dolomite, $(\mathbf{G})$ calcite, $(\mathbf{H})$ apatite, (I) fluorite, $(\mathbf{J})$ goethite, $(\mathbf{K})$ chromite, $(\mathbf{L})$ magnetite and $(\mathbf{M})$ hematite. False colour image (refer also to Figure 6). 
Table 4. Mineral discrimination using linear attenuation coefficient difference at $45.5 \mathrm{keV}$ effective energy in conjunction with grey value and density difference. $\mathrm{BH}=$ beam hardening.

\begin{tabular}{|c|c|c|c|c|c|}
\hline Mineral Comparison & $\begin{array}{c}\text { Filter } \\
\text { Material/BH } \\
\text { Correction } \\
\text { Factor } \\
\end{array}$ & $\begin{array}{c}\text { \% Grey Value } \\
\text { Difference }\end{array}$ & $\begin{array}{c}\text { \% Attenuation } \\
\text { Coefficient } \\
\text { Difference }\end{array}$ & $\begin{array}{l}\% \text { Density } \\
\text { Difference }\end{array}$ & Discrimination \\
\hline Almandine vs. Andradite & \multirow{3}{*}{$0.25 \mathrm{~mm} \mathrm{Cu} / 2$} & 18.8 & 14.2 & 10.7 & Yes \\
\hline Almandine vs. Grossular & & 18.2 & 53.0 & 15.5 & Yes \\
\hline Grossular vs. Andradite & & 33.6 & 45.2 & 5.44 & Yes \\
\hline Quartz vs. Kaolinite & \multirow{6}{*}{ No Filter/2 } & 4.31 & 9.42 & 1.89 & Partial \\
\hline Quartz vs. Dolomite & & 30.0 & 27.6 & 7.02 & Yes \\
\hline Quartz vs. Calcite & & 42.4 & 43.7 & 2.21 & Yes \\
\hline Kaolinite vs. Dolomite & & 26.8 & 34.4 & 8.77 & Yes \\
\hline Kaolinite vs. Calcite & & 39.8 & 49.0 & 4.06 & Yes \\
\hline Dolomite vs. Calcite & & 17.7 & 22.3 & 4.91 & Yes \\
\hline Fluorite vs. Apatite & $0.25 \mathrm{~mm} \mathrm{Cu} / 1$ & 9.26 & 6.06 & 0.63 & Yes \\
\hline Goethite vs. Chromite & $0.25 \mathrm{~mm} \mathrm{Cu} / 2$ & 7.10 & 13.0 & 10.7 & Partial \\
\hline Gothite vs. Magnetite & \multirow{5}{*}{$\begin{array}{l}1 \mathrm{~mm} \mathrm{Cu}+ \\
1 \mathrm{~mm} \mathrm{Al} / 3\end{array}$} & 34.2 & 26.8 & 17.4 & Yes \\
\hline Goethite vs. Hematite & & 37.1 & 25.7 & 18.6 & Yes \\
\hline Chromite vs. Magnetite & & 29.2 & 15.9 & 7.53 & Yes \\
\hline Chromite vs. Hematite & & 32.2 & 14.6 & 8.94 & Yes \\
\hline Magnetite vs. Hematite & & 4.27 & 1.42 & 1.52 & No \\
\hline
\end{tabular}

\section{Discussion}

The linear attenuation coefficient database developed above is a practical, user friendly tool for calculating linear attenuation coefficients. It is also very flexible in that it allows the user to calculate attenuation coefficients at any effective X-ray energy between $41.7 \mathrm{keV}$ and $74.6 \mathrm{keV}$ and this can be done offline. Comparison of the MXLAC database with that of the NIST online calculation tool indicates that the difference between the two is less than 5\%. MXLAC highlights the importance of knowing the exact mineral composition (in terms of specific cation and anion numbers) and density in order to predict which minerals can be discriminated and which cannot. In the following discussion, several examples of where MXLAC can be used to better set up XCT experiments are demonstrated.

\subsection{Mineral Composition and Linear Attenuation Coefficient}

For minerals with no solid solution, such as quartz, the calculation of the linear attenuation coefficient is straight forward as the chemical formula is fixed. In the case of quartz, which is $\mathrm{SiO}_{2}$, the linear attenuation coefficient is $0.93 \mathrm{~cm}^{-1}$ at $45.5 \mathrm{keV}$. However, for minerals with solid solution substitution, it is necessary to know the exact composition of the mineral in the sample being analysed. Garnet which is a common mineral in a variety of rocks elegantly illustrates this. The generic formula for garnet is $\mathrm{X}_{3} \mathrm{Y}_{2}\left(\mathrm{SiO}_{4}\right)_{3}$ with $\mathrm{X}$ representing $\mathrm{Mg}$, Fe, Mn or $\mathrm{Ca}$ and $\mathrm{Y}$ representing $\mathrm{Al}$ or $\mathrm{Cr}$ [28]. The example shown in Figure 4 is of a pyrope garnet, with the composition $\mathrm{Mg}_{3} \mathrm{Al}_{2} \mathrm{Si}_{3} \mathrm{O}_{12}$ and density $3.75 \mathrm{~g} / \mathrm{cm}^{3}$ and has the linear attenuation coefficient of $1.25 \mathrm{~cm}^{-1}$ at $45.5 \mathrm{keV}$ effective energy. This is distinct from garnet with different compositions such as almandine $\mathrm{Fe}_{3} \mathrm{Al}_{2} \mathrm{Si}_{3} \mathrm{O}_{12}\left(4.32 \mathrm{~g} / \mathrm{cm}^{3}\right.$, $\left.4.36 \mathrm{~cm}^{-1}\right)$, spessartine $\mathrm{Mn}_{3} \mathrm{Al}_{2} \mathrm{Si}_{3} \mathrm{O}_{12}\left(4.29 \mathrm{~g} / \mathrm{cm}^{3}, 4.16 \mathrm{~cm}^{-1}\right)$, andradite $\mathrm{Ca}_{3} \mathrm{Fe}^{3+}{ }_{2} \mathrm{Si}_{3} \mathrm{O}_{12}\left(3.86 \mathrm{~g} / \mathrm{cm}^{3}\right.$, $\left.3.74 \mathrm{~cm}^{-1}\right)$, uvarovite $\mathrm{Ca}_{3} \mathrm{Cr}_{2} \mathrm{Si}_{3} \mathrm{O}_{12}\left(3.85 \mathrm{~g} / \mathrm{cm}^{3}, 3.41 \mathrm{~cm}^{-1}\right)$, and grossular $\mathrm{Ca}_{3} \mathrm{Al}_{2} \mathrm{Si}_{3} \mathrm{O}_{12}\left(3.65 \mathrm{~g} / \mathrm{cm}^{3}\right.$, $2.05 \mathrm{~cm}^{-1}$ ) calculated at the same $\mathrm{X}$-ray energy. The difference in the linear attenuation coefficients is a result of differences in the densities and chemical compositions of these minerals even though the structural formula remains constant and the physical properties of all the garnet varieties remains very similar. As a consequence of the differences in linear attenuation coefficient, these minerals will appear differently on a 2D image slice except for almandine and spessartine due to a lower attenuation coefficient difference of $4.6 \%$.

The example given above assumes that garnet exists as one of the end-member compositions, but this is not usually the case, with garnet exhibiting solid solution substitution within both the $X$ and $Y$ cation sites. What this means in practice is that garnet in any given rock will have a linear attenuation 
coefficient of between $4.36 \mathrm{~cm}^{-1}$ and $1.25 \mathrm{~cm}^{-1}$ at $45.5 \mathrm{keV}$ depending on its exact composition. For example, a garnet that is dominantly Fe-rich but also containing appreciable amounts of $\mathrm{Mg}$ as well as minor amounts of $\mathrm{Mn}$ and $\mathrm{Ca}$ in the cation proportions $\left(\mathrm{Fe}_{2.1} \mathrm{Mg}_{0.7} \mathrm{Mn}_{0.15} \mathrm{Ca}_{0.05}\right) \mathrm{Al}_{2} \mathrm{Si}_{3} \mathrm{O}_{12}$ would have an approximate composite density of $4.16 \mathrm{~g} / \mathrm{cm}^{3}$ and a linear attenuation coefficient of $3.60 \mathrm{~cm}^{-1}$ at $45.5 \mathrm{keV}$. This is significantly different from the linear attenuation coefficient values for either end-member almandine or pyrope. Assuming a linear attenuation coefficient of either of these end-members would result in significant error associated with the differentiation of this garnet composition from other minerals with linear attenuation coefficients in this range at $45.5 \mathrm{keV}$. Similarly, using the density of one garnet composition, when in fact a different composition is present, will also result in the calculation of an incorrect linear attenuation coefficient.

\subsection{Mineral Density and Attenuation}

MXLAC can also be used to illustrate the importance of upfront mineral density and compositional information when differentiating minerals using XCT. To evaluate this issue, iron ore is considered where iron ore mineralisation involves both iron ore minerals themselves (hematite, magnetite and goethite) as well as commonly associated gangue minerals may be present (quartz, kaolinite, gibbsite, chlorite, siderite, ankerite, fluorite, barite and apatite). The theoretically calculated linear attenuation coefficients for these minerals (Table 5) were compared in order to evaluate the impact of different densities on the attenuation coefficient. This is well illustrated by barite $\left(\mathrm{BaSO}_{4}\right)$, which has a lower density $\left(4.48 \mathrm{~g} / \mathrm{cm}^{3}\right)$ than hematite and magnetite $\left(5.26\right.$ and $5.18 \mathrm{~g} / \mathrm{cm}^{3}$ ) respectively. These minerals have a minimum density difference $13.51 \%$ which suggest that barite should appear darker or with lower grey values than hematite and magnetite. However, this is not the case, because barite has a higher linear attenuation coefficient of $46.1 \mathrm{~cm}^{-1}$ at $45.5 \mathrm{keV}$ effective X-ray energy which would make it to appear brighter. In contrast, magnetite has a linear attenuation coefficient of $9.15 \mathrm{~cm}^{-1}$ while hematite is $9.02 \mathrm{~cm}^{-1}$. The linear attenuation coefficients of hematite and magnetite are similar because their densities and chemical composition are similar, Table 5. In addition to this the majority of the minerals with a density difference $<5 \%$ presented in Table 4 were partially or full distinguishable from each other. This emphasizes the need to use linear attenuation coefficient information to predict if minerals can be discriminated or not as compared to using the density information alone.

Table 5. Summary of common minerals in iron ores, alongside their formulae and density https: //www.mindat.org/.

\begin{tabular}{cccccc}
\hline Iron Mineral & Formula & Density $\mathbf{g} / \mathbf{c m}^{\mathbf{3}}$ & Gangue Mineral & Formula & Density g/cm \\
\hline Hematite & $\mathrm{Fe}_{2} \mathrm{O}_{3}$ & 5.26 & Quartz & $\mathrm{SiO}_{2}$ & 2.65 \\
Magnetite & $\mathrm{Fe}_{3} \mathrm{O}_{4}$ & 5.18 & Kaolinite & $\mathrm{Al}_{2} \mathrm{Si}_{2} \mathrm{O}_{5}(\mathrm{OH})_{4}$ & 2.60 \\
Goethite & $\mathrm{FeO}(\mathrm{OH})$ & 4.28 & Fluorite & $\mathrm{CaF}_{2}$ & 3.13 \\
Siderite & $\mathrm{FeCO}_{3}$ & 3.96 & Barite & $\mathrm{BaSO}_{4}$ & 4.48 \\
Chlorite & $(\mathrm{Mg})_{5} \mathrm{Al}_{2} \mathrm{Si}_{3} \mathrm{O}_{10}(\mathrm{OH})_{8}$ & 3.20 & Apatite & $\mathrm{Ca}_{5}\left(\mathrm{PO}_{4}\right)_{3} \mathrm{OH}$ & 3.19 \\
Pyrite & $\mathrm{FeS}_{2}$ & 5.01 & Gibbsite & $\mathrm{Al}_{2}(\mathrm{OH})_{3}$ & 2.34 \\
Ilmenite & $\mathrm{FeTiO}_{3}$ & 4.76 & Ankerite & $\mathrm{CaFe}\left(\mathrm{CO}_{3}\right)_{2}$ & 3.20 \\
\hline
\end{tabular}

\subsection{Influence of Mineral Composition vs. Density on Attenuation Coefficient}

Linear attenuation coefficients are much more strongly impacted by mineral composition than they are by density. This would suggest that it is much more important to obtain an accurate composition in order to optimize the discrimination between the minerals than it is to obtain an accurate density. This is illustrated using the example of olivine, which has a general structural formula of $(\mathrm{Mg}, \mathrm{Fe})_{2} \mathrm{SiO}_{4}$, and an average density of $3.3 \mathrm{~g} / \mathrm{cm}^{3}$. Olivine of this composition and density, has a linear attenuation coefficient of $4.20 \mathrm{~cm}^{-1}$ at an arbitrary effective energy of $41.7 \mathrm{keV}$, which is distinct from olivine of composition $\mathrm{Mg}_{1.6} \mathrm{Fe}_{0.4} \mathrm{SiO}_{4}$ with an attenuation coefficient of $2.6 \mathrm{~cm}^{-1}$ at the same energy and density. Swapping the ratio of magnesium and iron (i.e., $\mathrm{Mg}_{0.4} \mathrm{Fe}_{1.6} \mathrm{SiO}_{4}$ ) results in an attenuation coefficient of $5.49 \mathrm{~cm}^{-1}$, yielding an attenuation coefficient difference of $52.64 \%$ from the $\mathrm{Mg}_{1.6} \mathrm{Fe}_{0.4} \mathrm{SiO}_{4}$ composition when the same density is used for the calculations. When the same scenario is considered for $\mathrm{Mg}_{0.4} \mathrm{Fe}_{1.6} \mathrm{SiO}_{4}$ 
with a density reduction of $52.64 \%$ to $1.74 \mathrm{~g} / \mathrm{cm}^{-3}$ from its average density of $3.3 \mathrm{~g} / \mathrm{cm}^{3}$, its attenuation coefficient is $2.9 \mathrm{~cm}^{-1}$ which is $35.41 \%$ less than when the density is $3.3 \mathrm{~g} / \mathrm{cm}^{3}$. This means that a $52.64 \%$ reduction in density only resulted in a $32.42 \%$ reduction in attenuation coefficient for the same composition. Similarly, andradite and uvarovite garnets have almost identical densities (3.86 vs. $3.85 \mathrm{~g} / \mathrm{cm}^{-1}$ ) but linear attenuation coefficients of 4.88 and $4.31 \mathrm{~cm}^{-1}$ with a percentage attenuation coefficient difference of $11.68 \%$ at $41.7 \mathrm{keV}$. Using density information alone would suggest that these two minerals cannot be discriminated even though their linear attenuation coefficients suggest that they can be. Thus, a change in composition has more effect on the attenuation coefficient than a change in density and hence knowing the exact composition of the minerals to be interrogated with XCT is critical to evaluate whether XCT is an appropriate tool to use.

\section{Conclusions}

Theoretically calculated linear attenuation coefficients form an important basis for planning XCT scans with optimal image contrast. These attenuation coefficients can be utilised to optimise the X-ray scanning energy to discriminate minerals according to exact mineral compositions as well as density for proper quantification. The data bank presented here is designed not only to be user friendly and compare attenuation coefficient information of two different minerals at the same time but also to be easily available. The discrimination between minerals with an attenuation coefficient difference of less than $6 \%$ will be challenging. This will depend on the complexity of the minerals especially if they have inclusions as observed between quartz and kaolinite with grey values difference of $4.31 \%$ even though their attenuation coefficient difference is $>9 \%$. Optimal discrimination using attenuation coefficients depends more on the composition but also on scanning parameters including appropriate filter material being used. Different minerals respond differently on the type of filter material being used, especially those with a density greater than $3 \mathrm{~g} / \mathrm{cm}^{3}$. Minerals with a density less than $3 \mathrm{~g} / \mathrm{cm}^{3}$ might not require any application of filter materials in order to optimize discrimination. This depends on the sample size and complexity of the sample being scanned (mineral inclusion). This means that minerals of interest should be well defined and understood prior to scanning so that the limitations associated with discriminating minerals using linear attenuation coefficients can be evaluated before XCT scanning. However, the extent of mineral inclusions that affects discrimination and direct comparison between linear attenuation coefficient difference with grey value difference should be investigated in more detail in future studies. This will include studying how uniform and non-uniform distribution of mineral inclusions affects grey value difference that is supposed to correlate directly with the attenuation coefficient difference. In addition to this different detector filter materials that can minimise the impact of environmental scatter that contribute to inaccurate mineral grey values should also be investigated in order to obtain the expected grey value difference that correlates with the attenuation coefficient difference. This will allow effective utilization or application of the XCT technique to the geological samples. The effective application of the XCT techniques together with the MXLAC spreadsheet is not only important for geological samples but also to any research field that studies attenuating materials of any kind, e.g., material sciences, electrochemical studies, etc. Most importantly understanding the limitations of XCT will lead to further refinements of the XCT technique that may in the future overcome these limitations.

Supplementary Materials: The following are available online at http://www.mdpi.com/2075-163X/10/5/441/s1, The MXLAC spreadsheet to calculate the linear attenuation coefficient with a title 'MXLAC-A tool to calculate linear attenuation coefficient' is included.

Author Contributions: L.C.B.: Conceptualization, analysis, methodology and writing-original draft. J.A.M.: Methodology, supervision and writing-review \& editing. M.B.: Methodology, supervision and writing-review \& editing. All authors have read and agreed to the published version of the manuscript.

Funding: The authors would like to thank Necsa (Nuclear Energy Corporation of South Africa) and the management team for funding and access to the Microfocus system in the MIXRAD Lab, which is a DST-NRF (Department of Science and Technology-National Research Funding) funded facility through the NEP-RISP (National Equipment Programme-Research Infrastructure Support Programmes) program. The project is 
supported through SAMMRI (South African Minerals to Metals Research Institute), grant number: S1511. This project is also based on the research supported in part by the National Research Foundation of South Africa (Grant Numbers 86054, 99005). Any opinions, findings and conclusions or recommendations expressed in any publication generated by the NRF supported research is that of the author(s), and that the NRF accepts no liability whatsoever in this regard.

Acknowledgments: The authors would like to thank Andrew Watson for assistance with compiling the diagrams, Madelaine Frazenburg for SEM-EDS analysis at SU and Gaynor Yorath and the UCT QEMSCAN team for assistance with QEMSCAN analysis.

Conflicts of Interest: The authors declare no conflict of interest.

\section{References}

1. Momose, A.; Keiichi, H. The possibility of phase-contrast X-ray microtomography. Jpn. J. Appl. Phys. 1999, 38, 625. [CrossRef]

2. Mees, F.; Swennen, R.; Van Geet, M.; Jacobs, P. (Eds.) Applications of X-ray Computed Tomography in the Geosciences, 215th ed.; The Geological Society London: London, UK, 2003; ISBN 1862391394.

3. Ketcham, R.A.; Carlson, W.D. Acquisition, optimization and interpretation of X-ray computed tomographic imagery: Applications to the geosciences. Comput. Geosci. 2001, 27, 381-400. [CrossRef]

4. Kalender, W.A. X-ray computed tomography. Phys. Med. Biol. 2006, 51, R29-R43. [CrossRef] [PubMed]

5. Cnudde, V.; Masschaele, B.; Dierick, M.; Vlassenbroeck, J.; Van Hoorebeke, L.; Jacobs, P. Recent progress in X-ray CT as a geosciences tool. Appl. Geochem. 2006, 21, 826-832. [CrossRef]

6. Hamdani, A.H. X-ray computed tomography analysis of sajau coal, Berau Basin, Indonesia: 3D imaging of cleat and microcleat characteristics. Int. J. Geophys. 2015. [CrossRef]

7. Kyle, J.R.; Ketcham, R.A. Application of high resolution X-ray computed tomography to mineral deposit origin, evaluation, and processing. Ore Geol. Rev. 2015. [CrossRef]

8. Siddiqui, I.; Solangi, S.H.; Soomro, A.A.; Warar, M.A.; Samoon, M.K.; Ajmal, S. Application of X-ray computed tomography for analyzing cleats and pores for coalbed methane in coal from thar coalfield. Can. J. Pure Appl. Sci. 2014, 8, 2743-2749.

9. Panahi, H.; Kobchenko, M.; Renard, F.; Mazzini, A.; Scheibert, J.; Dysthe, D.; Jamtveit, B.; Malthe-Sorensses, A.; Meakin, P. A 4D synchrotron X-ray-tomography study of the formation of hydrocarbon-migration pathways in heated organic-rich shale. Soc. Pet. Eng. J. 2012, 18, 366-377. [CrossRef]

10. Miller, J.A.; Faber, C.; Rowe, C.D.; Macey, P.H.; du Plessis, A. Eastward transport of the Monapo Klippe, Mozambique determined from field kinematics and computed tomography and implications for late tectonics in central Gondwana. Precambrian Res. 2013, 237, 101-115. [CrossRef]

11. Kaufhold, A.; Zacher, G.; Halisch, M.; Kaufhold, S. X-ray computed tomography investigation of structures in opalinus clay from large scale to small scale after mechanical testing. Solid Earth 2016, 7, 1-19. [CrossRef]

12. Backeberg, N.R.; Iacoviello, F.; Rittner, M.; Mitchell, T.M.; Jones, A.P.; Day, R.; Wheeler, J.; Shearing, P.R.; Vermeesch, P.; Striolo, A. Quantifying the anisotropy and tortuosity of permeable pathways in clay-rich mudstones using models based on X-ray tomography. Sci. Rep. 2017, 7, 1-12. [CrossRef] [PubMed]

13. Iacoviello, F.; Lu, X.; Mitchell, T.M.; Brett, D.J.L.; Shearing, P.R. The imaging resolution and Knudsen effect on the mass transport of shale gas assisted by multi-length scale X-ray computed tomography. Sci. Rep. 2019, 9, 1-10. [CrossRef] [PubMed]

14. Ma, Y.; Zhong, N.; Cheng, L.; Pan, Z.; Dai, N.; Zhang, Y.; Yang, L. Pore structure of the graptolite-derived OM in the Longmaxi Shale, southeastern Upper Yangtze Region, China. Mar. Pet. Geol. 2016, 72, 1-11. [CrossRef]

15. Ashi, J. Computed tomography scan image analysis of sediments. In Ocean Drilling Program, Scientific Results; Shipley, T.H., Ogawa, Y., Blum, P., Bahr, J.M., Eds.; Integrated Ocean Drilling Program: College Station, TX, USA, 1997; Volume 156, pp. 151-159.

16. Tanaka, A.; Nakano, T.; Ikehara, K. X-ray computerized tomography analysis and density estimation using a sediment core from the Challenger Mound area in the Porcupine Seabight, off Western Ireland. Earth Planets Space 2011, 63, 103-110. [CrossRef]

17. Le Roux, S.G.; Du Plessis, A.; Rozendaal, A. The quantitative analysis of tungsten ore using X-ray microCT: Case study. Comput. Geosci. 2015, 85, 75-80. [CrossRef] 
18. Jardine, M.A.; Miller, J.A.; Becker, M. Coupled X-ray computed tomography and grey level co-occurrence matrices as a method for quantification of mineralogy and texture in 3D. Comput. Geosci. 2018, 111, 105-117. [CrossRef]

19. Sprawls, P. Physical Principles of Medical Imaging, 2nd ed.; Aspen Publishers: Gaithersburg, MD, USA, 1993; ISBN 1523-1739.

20. Bam, L.C.; Miller, J.A.; Becker, M.; De Beer, F.C.; Basson, I. X-ray computed tomography—Determination of rapid scanning parameters for geometallurgical analysis of iron ore. In Proceedings of the third AusIMM International Geometallurgy Conference, Perth, Australia, 15-17 June 2016; pp. 209-219.

21. Mccullough, E.C. Photon attenuation in computed tomography. Med. Phys. 1975, 2, 307-320. [CrossRef]

22. Matsubara, K.; Ichikawa, K.; Murasaki, Y.; Hirosawa, A.; Koshida, K. Accuracy of measuring half- and quarter-value layers and appropriate aperture width of a convenient method using a lead-covered case in X-ray computed tomography. J. Appl. Clin. Med. Phys. 2014, 15, 309-316. [CrossRef]

23. Yada, N.; Onishi, H. Validation of computed tomography-based attenuation correction of deviation between theoretical and actual values in four computed tomography scanners. Asia Ocean. J. Nucl. Med. Biol. 2016, 4, 81-819. [CrossRef]

24. Olarinoye, I. Variation of effective atomic numbers of some thermoluminescence and phantom materials with photon energies. Res. J. Chem. Sci. 2011, 1, 64-69.

25. Akça, B.; Erzeneoğlu, S.Z. The mass attenuation coefficients, electronic, atomic, and molecular cross sections, effective atomic numbers, and electron densities for compounds of some biomedically important elements at 59.5 kev. Sci. Technol. Nucl. Install. 2014, 2014, 1-9. [CrossRef]

26. McCullough, E.C.; Baker, H.L.; Wayne Houser, O.; Reese, D.F. An evaluation of the quantitative and radiation features of a scanning X-ray transverse axial tomograph: The EMI scanner. Radiology 1974, 111, 709-715. [CrossRef] [PubMed]

27. Tsuchiyama, A.; Hanamoto, T.; Nakashima, Y.; Nakano, T. Quantitative evaluation of attenuation contrast of minerals Tsuchiyama 2000.pdf. J. Miner. Pet. Sci. 2000, 95, 125-137. [CrossRef]

28. Deer, W.A.; Howie, R.A.; Zussman, J. An Introduction to the Rock-Forming Minerals, 2nd ed.; Pearson Prentice-Hall: London, UK, 1992. 